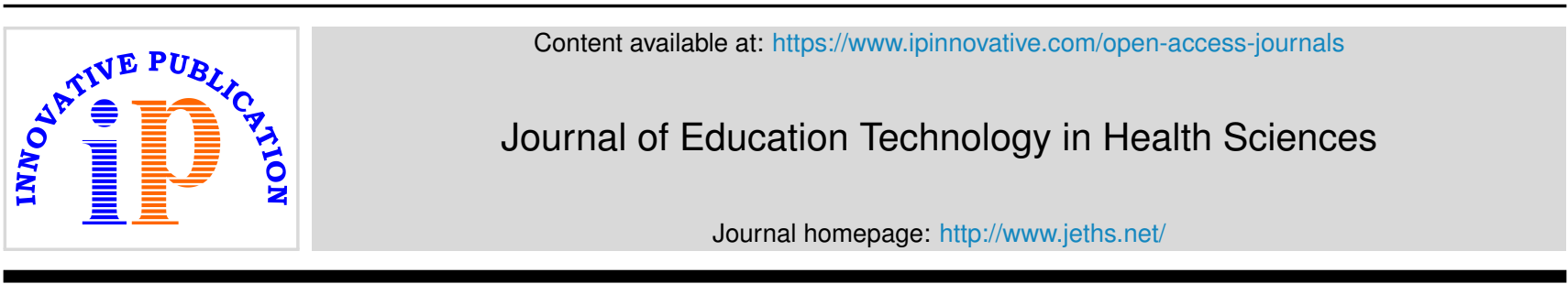

Original Research Article

\title{
A study on faculty perception about impact of basic medical education training and the need for further reinforcement
}

\author{
Joe Mathew ${ }^{1}$ * \\ ${ }^{1}$ Dept. of General Surgery, Pushpagiri Institute of Medical Sciences and Research Centre, Tiruvalla, Kerala, India
}

\section{A R T I C L E I N F O}

\section{Article history:}

Received 09-02-2021

Accepted 15-04-2021

Available online 17-05-2021

\section{Keywords:}

Medical education training

assessment

Reinforcement of medical teachers training

Dovetailing of training to suite the

teacher

Faculty perception

\begin{abstract}
A B S T R A C T
Background: Medical educational training activity has been going on and is gaining momentum and upgrading with time. One of the important means by which this is done in our country is the basic medical education course and presently its revised versions.

Objectives: We have to assess how far we have come close to our target or goal, what are the things we have actually achieved by it and what we have to achieve as yet.

Materials and Methods: We tried to do this assessment not by conducting an objective test among faculty or a performance assessment by students, but by a study conducted among the faculty by means of a questionnaire which uses faculty perceptions as recorded voluntarily as a means to our study. A few of the faculty chose to personally discuss issues addressed in the questionnaire.

Results and Conclusions: Majority of the faculty had a positive opinion, and definitely agreed that it is very effective, but insufficient to achieve the high aims it purports to achieve, because of insufficient training time, not being able to choose deeper reinforcement of what is interesting them, and devoting time towards only topics that appear to be of equal relevance to all, and not actually helping them along in what is of specific importance their speciality. Most of them thought that sufficient reinforcement of medical education training is an imperative issue.

(C) This is an open access article distributed under the terms of the Creative Commons Attribution License (https://creativecommons.org/licenses/by/4.0/) which permits unrestricted use, distribution, and reproduction in any medium, provided the original author and source are credited.
\end{abstract}

\section{Introduction}

A lot of faculty has undergone Basic or revised basic medical education training course as per MCI guidelines in our institution. At least 6 batches of 30 each have undergone training in the campus of Pushpagiri. A lot more have attended the course at the nodal centre. Of course all these do not convert to sample size as there are many who have repeated the course twice or more.

Most of the evaluations done hitherto were only short term assessments, usually based on questionnaire given immediately before the course and immediately afterward. Our aim is to conduct a relatively long term assessment.

\footnotetext{
* Corresponding author.

E-mail address: joe.acme7.kottayam@gmail.com (J. Mathew).
}

\section{Research Question}

What is being achieved by present Basic medical education training activities? To find out faculty perceptions about this as well as what further activity is required to fill the gap between the requirements of medical education and what is being achieved.

\section{Aims and Objectives}

1. To identify the attitudes and extend of practice of knowledge gained from basic medical education course among the faculty who have done the course.

2. To identify what change in instructional or assessment behaviour it has brought about.

3. To identify hindrances in carrying out the practice.

4. To generate suggestions, this would help in planning further faculty development workshops. 


\section{Review of Literature}

Mahler identifies the problem succinctly: the impact of the training upon actual teaching is not always quantitatively assessed, and the duration for which his effect is sustained is seldom measured. ${ }^{1}$

It is also unknown to what extent the magnitude and variability depend upon the content of the workshop, the training methods used, the participant's variability or the assessment procedures. ${ }^{2}$

Consequently, no knowledgeable decisions can be made as to the optimal time for reinforcements, although such booster interventions are generally recommended. 3,4

It has been found that preclinical staff and clinical staff find different sections of the faculty training programmes useful in their teaching practice, so faculty training programmes for the two categories can be taken separately so that both will find their training relevant and time can be spent more effectively and efficiently.

Faculty members working at preclinical departments found the topics on interactive teaching, demonstration, coaching, and use of structured learning and assessment guides less useful, because they are involved mostly in large group lectures. ${ }^{5}$

Junior faculty members on the other hand found demonstration and coaching more beneficial, because they are more involved in skills training than full time professors.

Clinicians benefited more from topics in student assessment course and could apply the structured learning and assessment guides, structured oral examination and objective structured clinical examination more efficiently than peers from their preclinical departments.

\section{Materials and Methods}

\subsection{Design}

Observational study.

\subsection{Setting}

Pushpagiri Medical College, Tiruvalla.

\subsection{Sample size}

67.

\subsection{Inclusion criteria}

All faculty who have undergone Basic Medical Education training who could be met with in the stipulated time, and who agreed to fill in the questionnaire.

\subsection{Exclusion criteria}

Any faculty unwilling to fill the questionnaire or not available to do it.

\subsection{Methodology}

A literature review was done and the study questionnaire was prepared, submitted before and discussed with the medical education faculty, of our college and the mentors at the nodal centre, before submitting the research proposal to IRB. Once IRB approval was obtained, the faculty were met with, project explained to them and questionnaire distributed to all willing and available to fill up the questionnaire. The answers were collected after a minimum of two days to allow the faculty enough time to deliberate on the questions asked.

The responses were analysed using excel software.

\subsection{Ethical considerations}

The study proposal was approved by Institutional Review Board with Reference No. 10/2019 dated $25^{\text {th }}$ February 2019.

\section{Results}

The questionnaire has two parts, first part basically shows the characters of the sample of participants.

The second part shows the results of the study.

The total number of participants is 67 .

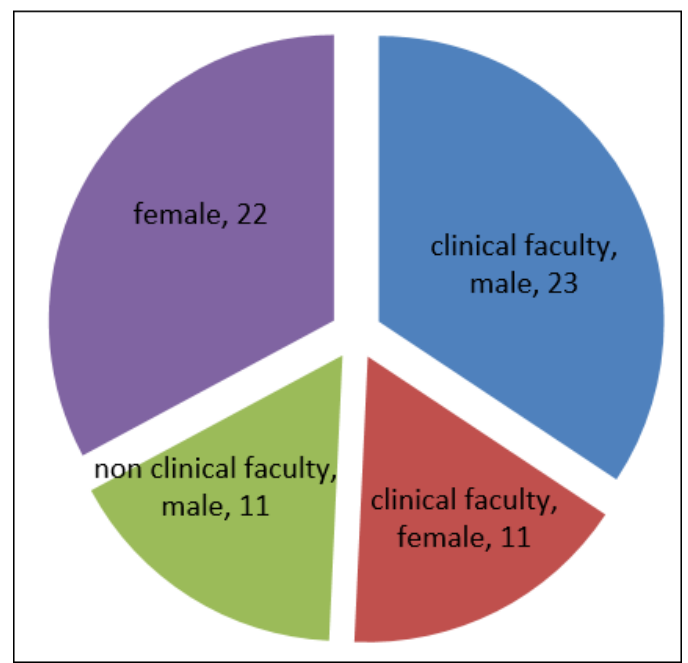

Fig. 1: Clinical/non clinical, male/female distribution

\subsection{Designation of teachers}

32 were professors, 13 associate professors and 22 assistant professors.

\section{Discussion}

There are three things to be discussed.

1. What are the ways you can assess the impact of medical faculty training programmes? If video recordings 


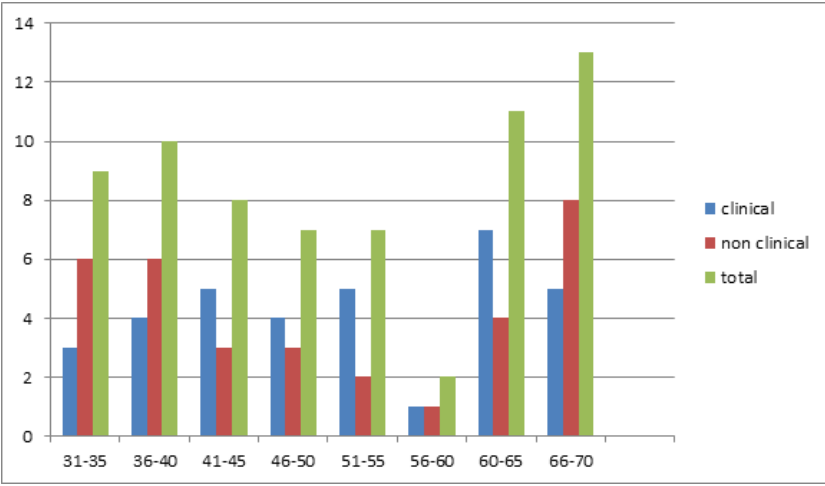

Fig. 2: Age of the teacher

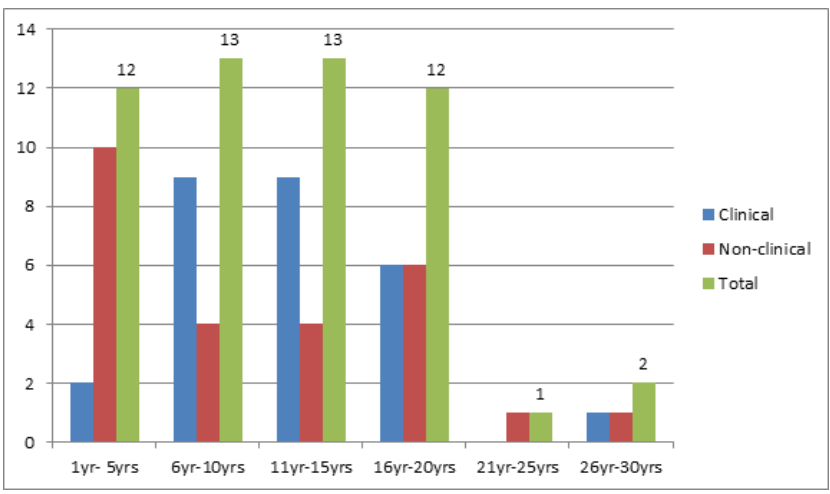

Fig. 3: Years of teaching experience

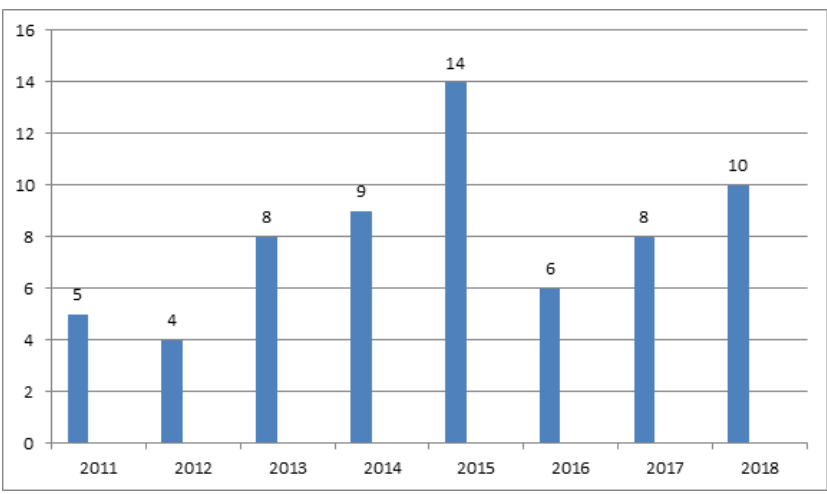

Fig. 4: Year of attending basic/revised basic course last

of all the lectures in an institute done in the lecture halls were to be available, they can be used to verify the use of SLOs and of the lesson planning and all round performance of teachers, assess their delivery by themselves or if they want, by peers and to ask for critical evaluation by medical educators who can provide adequate backup for improvement.

There is scope for improvement by oneself as long as one is aware of one's own inadequacies and one has he drive to improve on it. One needs to be helped by an

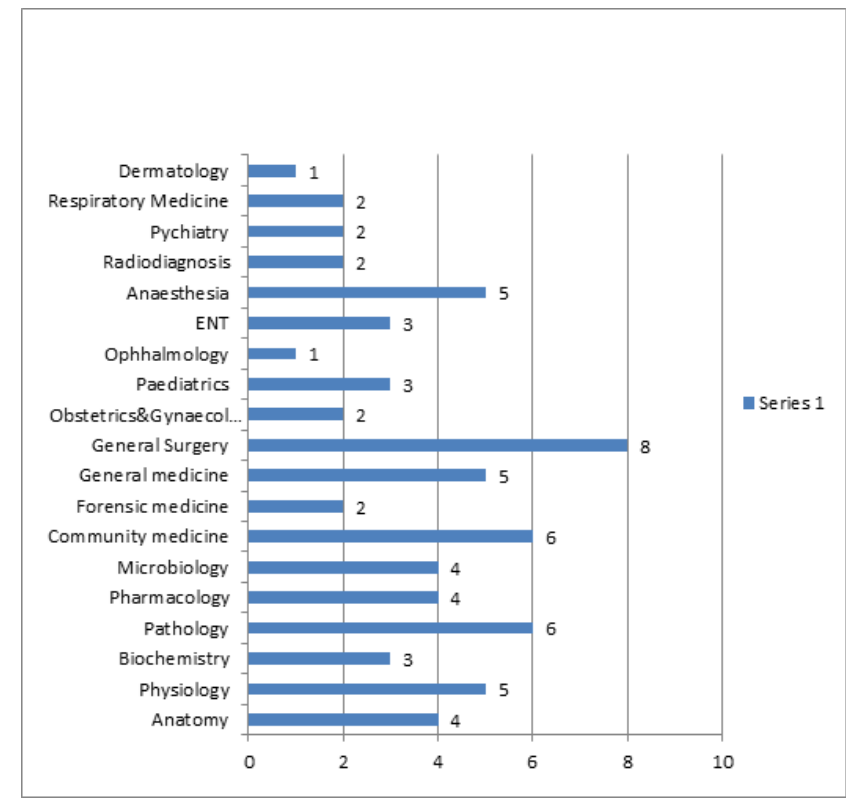

Fig. 5: Departments

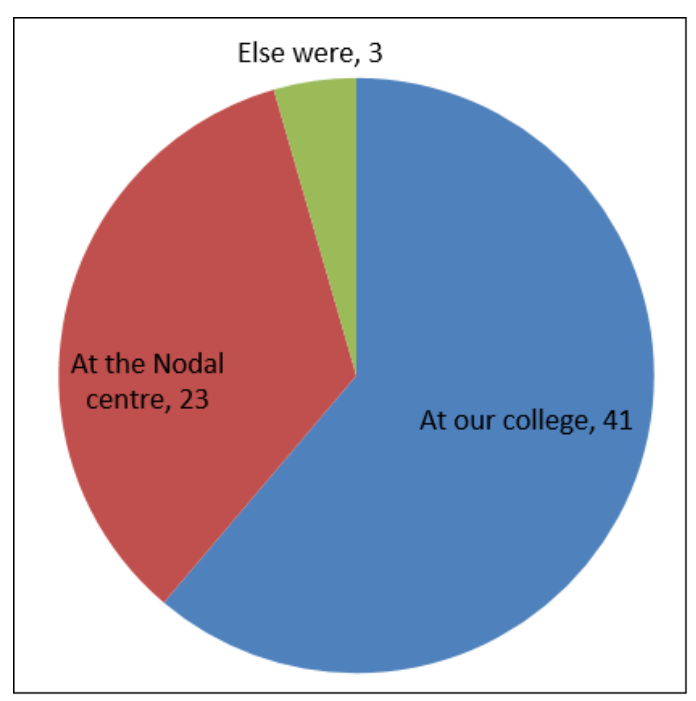

Fig. 6: Where did you attend the basic/revised basic course?

educator if one feels helpless in affecting the improvement one would like to have. It is when you are unconscious of your incompetence that the system requires interference by another educator.

Another method of assessment is opinions of faculty at large being collected together using questionnaire to find the overall as well as individual opinions.

Did participation in the program lead to increased knowledge of instructional methods?

Did the teacher's attitude towards teaching, like motivation, approach, confidence etc. increase?

Do they construct teaching modules, with SLOs and lesson plans? 


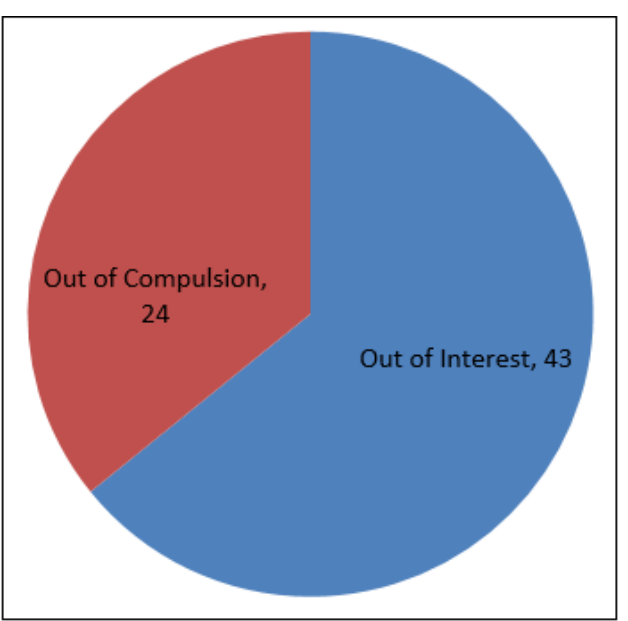

Fig. 7: Did you attend the course out of interest or out of compulsion?

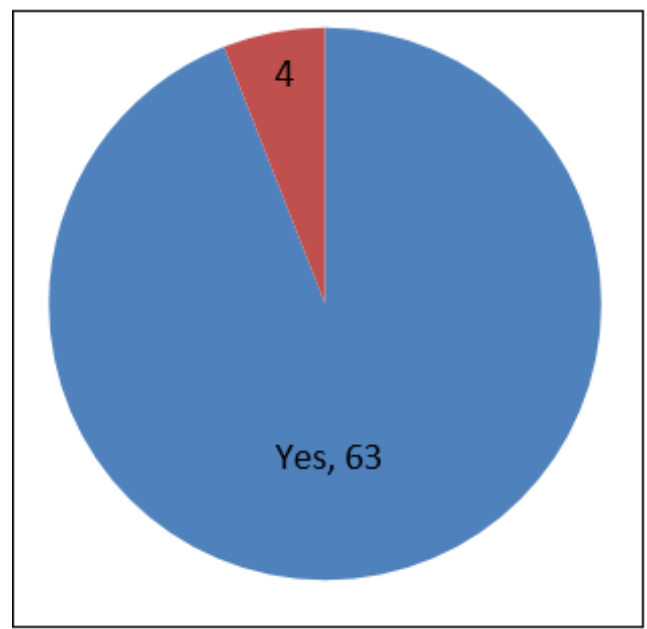

Fig. 8: After attending the course, did you find it worth attending?

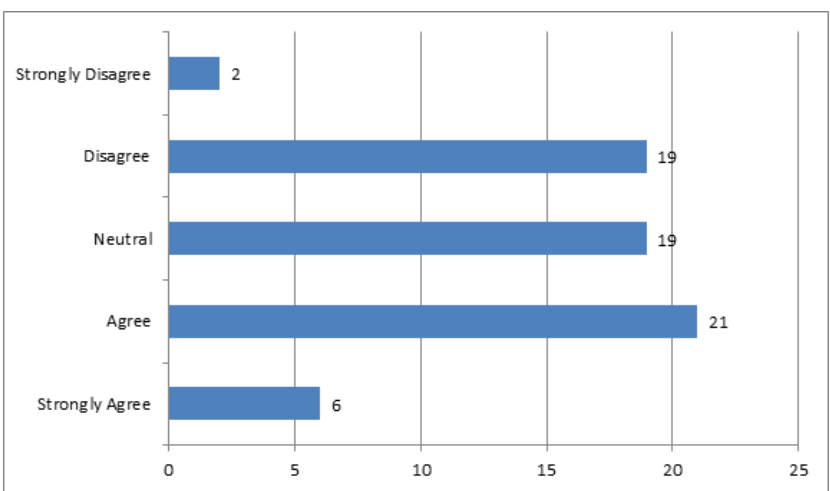

Fig. 9: Do you think that some part of the course material was irrelevant to teaching of your subject?

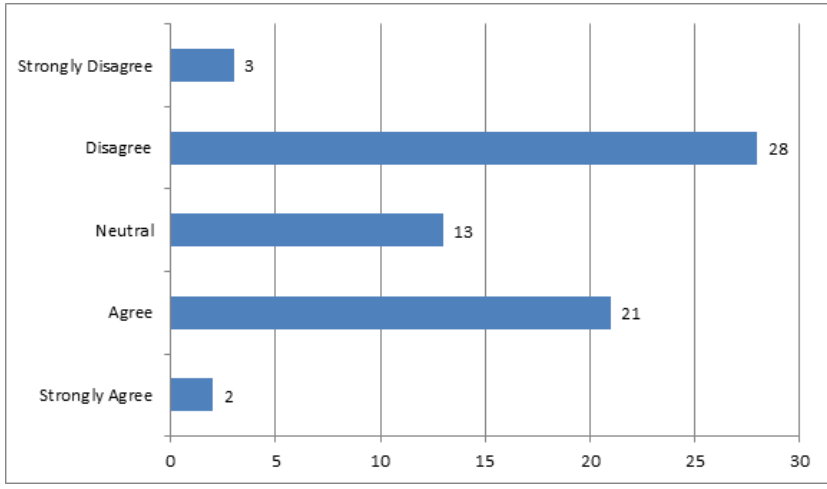

Fig. 10: Do you think too many topics have been covered in too short a time?

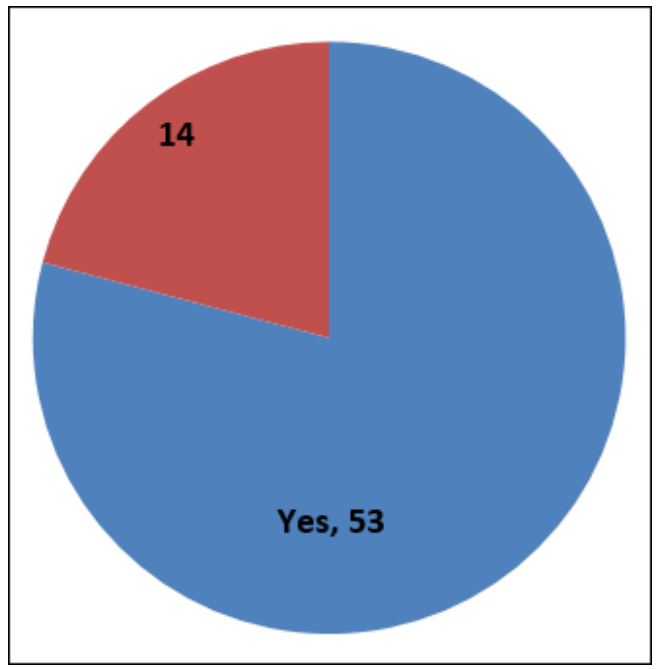

Fig. 11: Did it bring any change in your perspective of medical education?

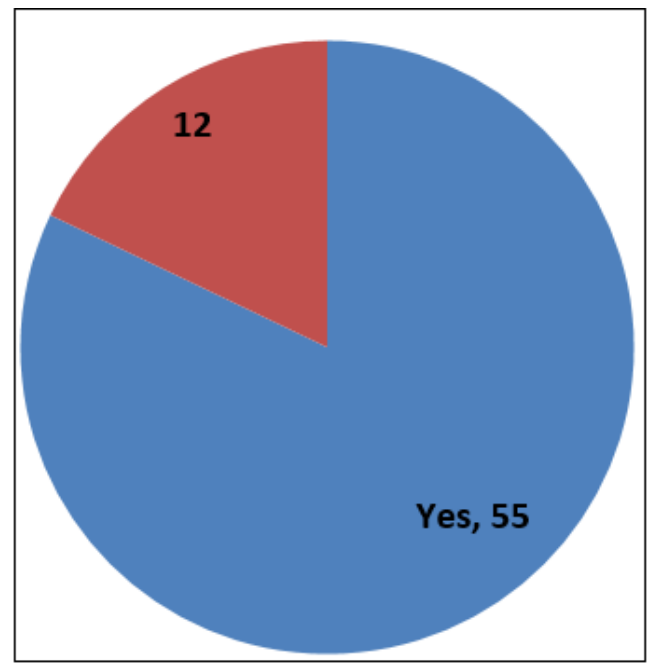

Fig. 12: Did it bring any change in your teaching methodology? 


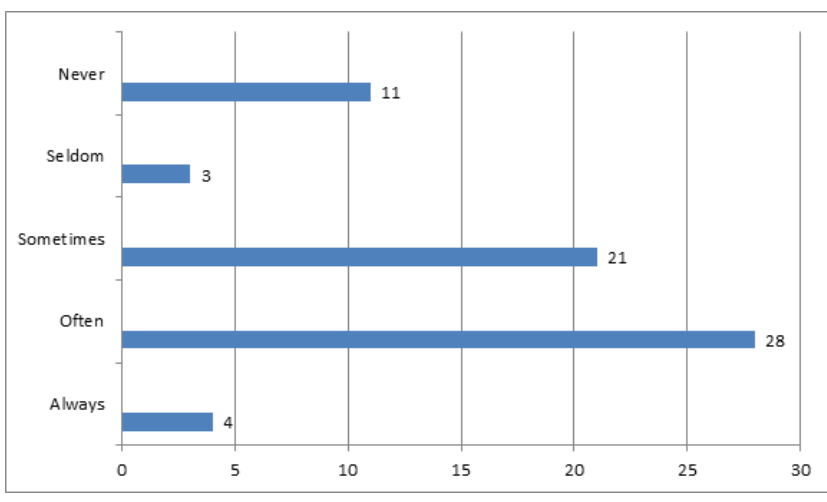

Fig. 13: If yes, whether you were able to implementit?

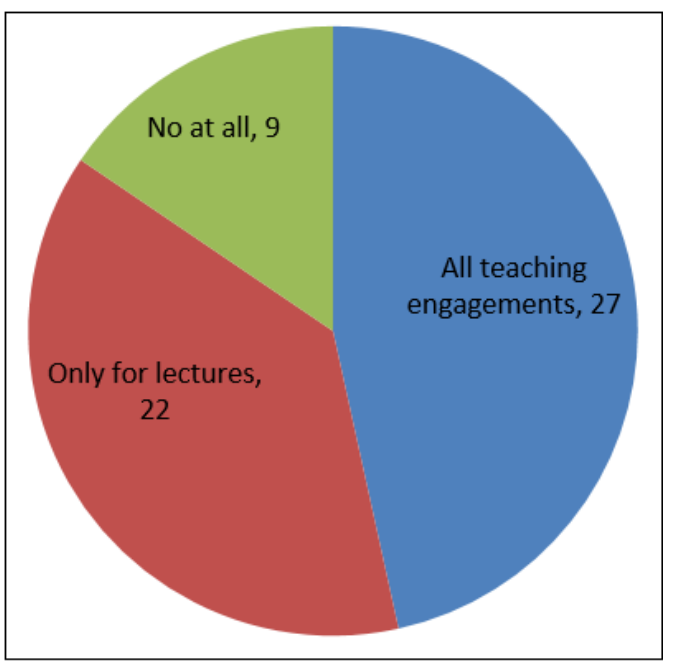

Fig. 14: Are you preparing SLOs for each teaching engagement, or only for lectures or not at all?

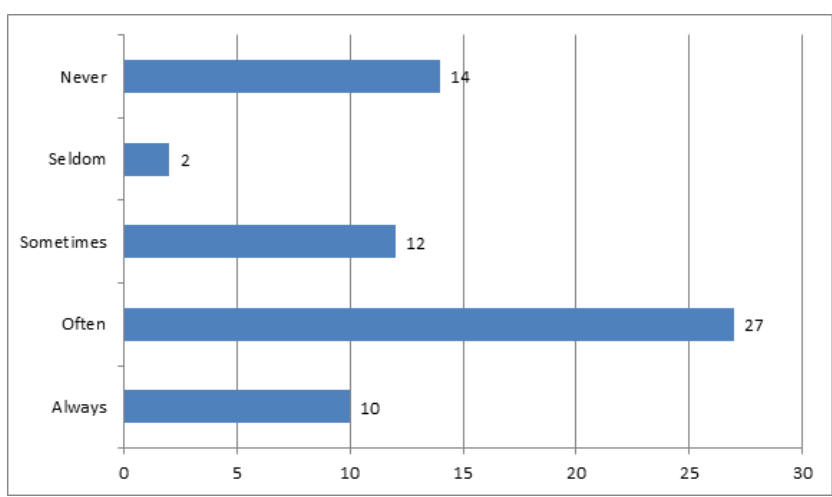

Fig. 15: If you are preparing SLOs how often do you prepare?

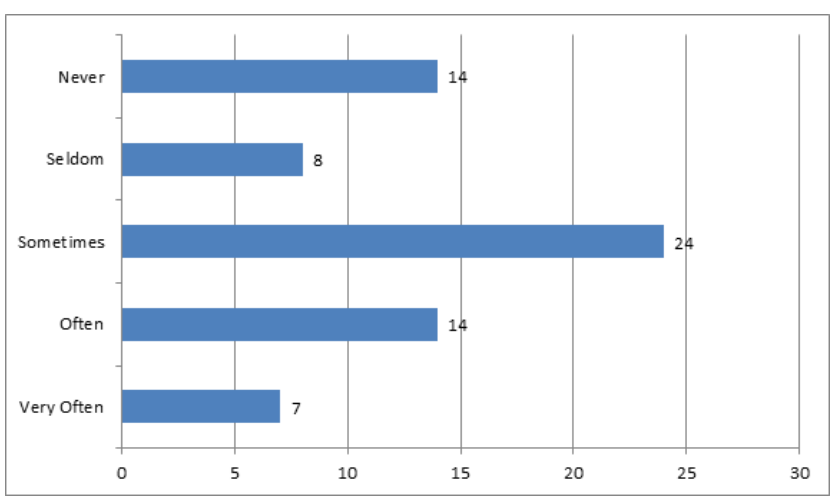

Fig. 16: Are you preparing OSCEs or OSPEs and using them for assessment in your department?

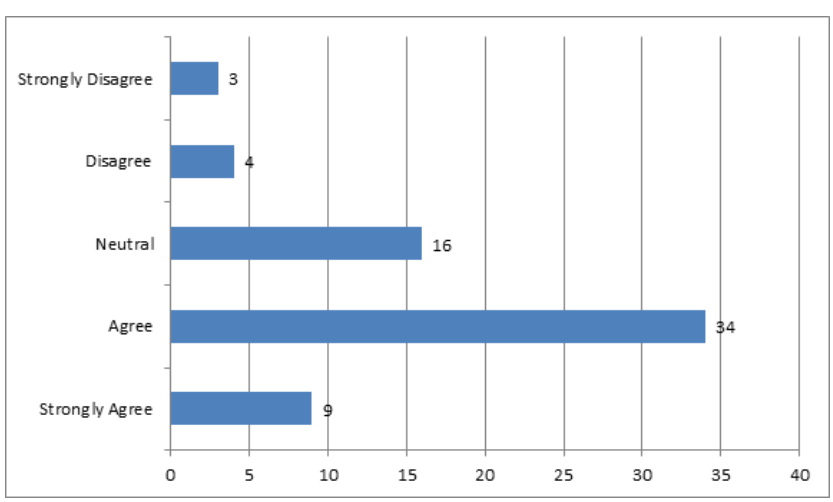

Fig. 17: Do you feel further reinforcement or training is required for effective practice of these newer methods?

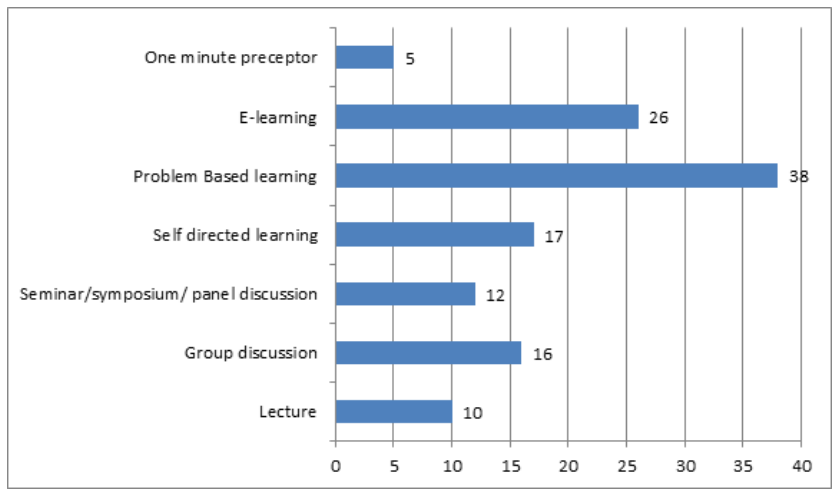

Fig. 18: Which of the following teaching learning methods would you like to know more about? 


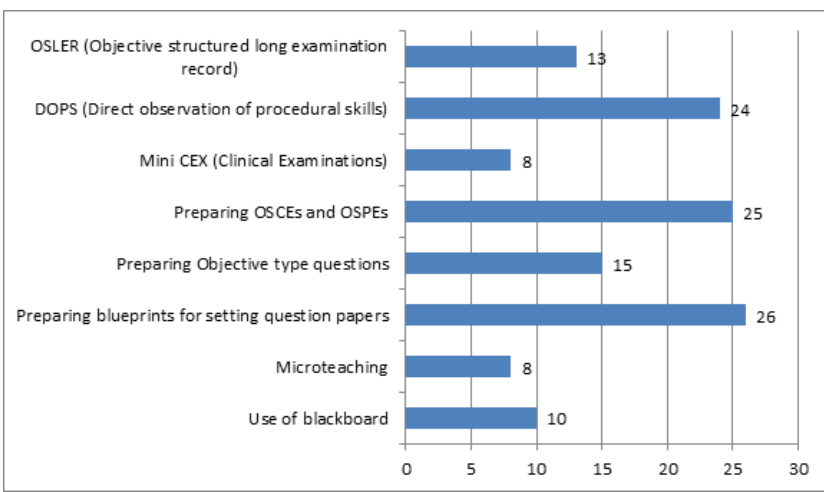

Fig. 19: Which of these skills would you like to acquire or know more if given the opportunity?

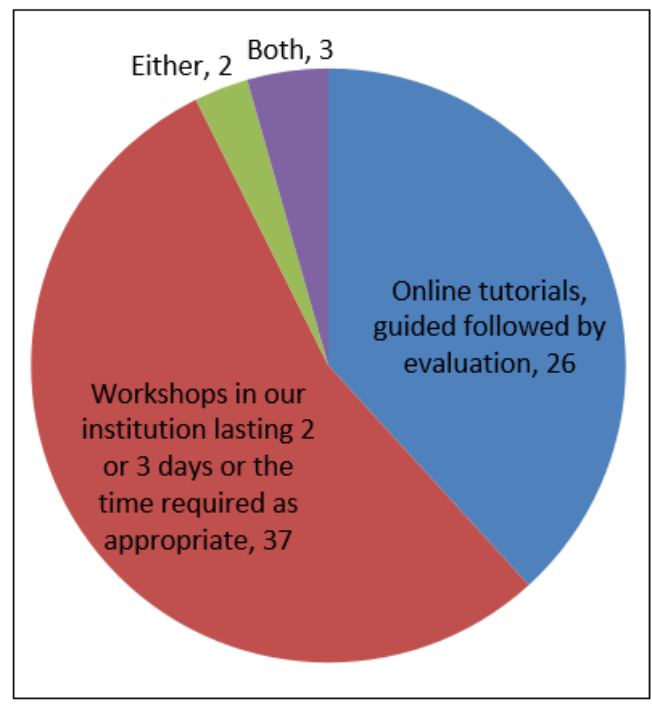

Fig. 20: Which method are you willing to use in acquiring the above?

Did their methods of and attitude towards assessment and evaluation change?

Do they ever consider using of peers to provide feedbacks for improvement?

Overall effect of education can be made by assessment of performance of the student immediately and in the long term. Effective long term transference of a competency is the best way to assess the educational process.

2. The second thing to be discussed is the sampling range of this study. There is an almost equal number of preclinical and clinical teachers, equal distribution of males and females, of departments, designation of faculty, range of teaching experience, and nearness and distance of having gone through the training programme in terms of years, and their being trained in the college or at the nodal centre.

3 . Though a large number answered that they attended the programme out of compulsion most of them thought that the programme was useful and worth attending after they went through it. For those who have undergone the program just once, the effects more or less was confined to their change of attitude as teachers, with an increase in level of confidence and a change of approach to students and teaching, and thus exposure of veteran teachers to these programmes did not make them gain any thing as they already had these attributes. They admitted to the definite need of reinforcement programmes.

But those who have gone through this process of training more than once, definitely started making changes or at least attempted to make them in their teaching methods and spend time trying to plan lessons, blaming less of practice or nonpracticing of what they learned to lack of time. They were the ones who were more enthusiastic about reinforcement programmes.

Those who have done the programme thrice and those in the medical education unit and those who did the advanced course were all into much stronger practice of what they learned.

This definitely proves one thing: any amount of reinforcement or guided practice against time limits definitely makes a telling difference in the performance of the educators.

Not all the methods of teaching and learning as well as assessment are relevant to the entire faculty. So, teachers training workshops conducted for everyone tends to concentrate only on things which are relevant to the entire faculty. This leaves out many new things and methods for which and on which the time devoted is totally inadequate. So, populations with similar interests should be trained together, separately, from those who do not share them.

Most of the teachers chose workshops as a means of reinforcement programmes as against online tutorials.

\section{Conclusion}

Medical education efforts are definitely having a positive effect but require planned dovetailed reinforcement efforts for bearing its full fruit.

\section{Source of Funding}

None

\section{Conflict of Interest}

None.

\section{References}

1. Mahler S, Benor DE. Short and long term effects of a teachertraining workshop in medical school. Higher Educ. 1984;13(3):265-73.

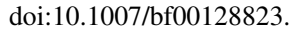

2. Gall MD, Dunning B. Minicourse 9: Higher cognitive questioning. McMillan Educational Services; 1967.

3. Bland CJ. Faculty Development through Workshops. Springfield: Charles C Thomas Publisher; 1980.

4. Foley RP, Smilansky J. Teaching Techniques: A Handbook for Health Professionals. New York: McGraw Hill Inc; 1980. 
5. Sarikaya O, Kalaca S, Yegen B, Cali S. The impact of faculty development program: Evaluation based on self-assessment by medical educators from preclinical and clinical disciplines. Adv Physiol Educ.

Cite this article: Mathew J. A study on faculty perception about impact 2010;34:34-40.

\section{Author biography}

Joe Mathew, Associate Professor

of basic medical education training and the need for further
reinforcement. $J$ Educ Technol Health Sci 2021;8(1):16-22. 